\title{
The prognosis impact of hyperthermic intraperitoneal chemotherapy (HIPEC) plus cytoreductive surgery (CRS) in advanced ovarian cancer: the meta-analysis
}

\author{
Guyu Zhang ${ }^{1+}$, Yimin Zhu ${ }^{2+}$, Chongdong Liu ${ }^{1}$, Guangming Chao ${ }^{1}$, Ran Cui ${ }^{1}$ and Zhenyu Zhang ${ }^{1 *}$
}

\begin{abstract}
Background and objective: Previous studies about the prognostic value of the HIPEC have yielded controversial results. Therefore, this study aims to assess the impact of HIPEC on patients with ovarian cancer.

Results: We included 13 comparative studies, and found that the overall survival (OS) and progression-free survival (PFS) in HIPEC groups were superior to groups without HIPEC treatment in the all total population (HR=0.54,95\% Cl:0.45 to $0.66, \mathrm{HR}=0.45,95 \% \mathrm{Cl}: 0.32$ to 0.62 ). Additionally, the subgroup analysis showed that patients with advanced primary ovarian cancers also gained improved OS and PFS benefit from HIPEC ( $\mathrm{HR}=0.59,95 \% \mathrm{Cl}: 0.46$ to $0.75, \mathrm{HR}=0.41,95 \% \mathrm{Cl}: 0.32$ to 0.54 ). With regard to recurrent ovarian cancer, HIPEC was associated with improved OS (HR $=0.45,95 \%$ Cl:0.24 to 0.83 ), but for the PFS, no correlation was observed between HIPC group and the non-HIPEC group (HR $=0.55,95 \%$ Cl:0.27 to 1.11). HIPEC also led to favorable clinical outcome (HR=0.64,95\% Cl:0.50 to 0.82 , $\mathrm{HR}=0.36,95 \%$ Cl:0.20 to 0.65) for stage III or IV ovarian cancer with initial diagnosis.

Conclusion: The review indicated that HIPEC-based regimens was correlated with better clinical prognosis for patients with primary ovarian cancers. For recurrent ovarian cancers, HIPEC only improved the OS but did not elicit significant value on the PFS.
\end{abstract}

Keywords: HIPEC, Hyperthermic intraperitoneal chemotherapy, CRS, Cytoreductive surgery, Ovarian cancer, Meta-analysis, Review

\section{Introduction}

Ovarian cancer $(\mathrm{OC})$ is one of the most lethal gynecologic cancers with 22,440 new cases and 14,080 deaths anticipated by 2017 in the United States [1]. Surgery is the optimal treatment for early-stage ovarian cancer, and platinum-based chemotherapy followed by debulking surgery is the standard therapy for advanced ovarian cancer. Although the development of surgery and chemotherapy improved clinical outcomes of patients with advanced ovarian cancer, the 5-year survival rate of less than $30 \%$ was still difficult to overcome. Due to the lack of specific

\footnotetext{
* Correspondence: Zhenyuzhang2000@163.com

${ }^{\dagger}$ Guyu Zhang and Yimin Zhu contributed equally to this work.

'Department of Obstetrics and Gynecology, Beijing Chaoyang Hospital,

Capital Medical University, No.8, industrial south road, Chaoyang District, Beijing, China

Full list of author information is available at the end of the article
}

clinical symptom and the characteristic of spreading to the abdominal cavity, most of OC have spread to peritoneum by the time of preliminary diagnosis [2]. The natural feature of OC provided a perfect opportunity to develop the local therapy. A systematic review showed that intraperitoneal (IP) chemotherapy prolonged survival time and reduced the risk of death. After every cycle of IP chemotherapy finished, the risk of death decreased by $12 \%$ [3]. Despite the positive clinical achievement, a higher rate of adverse events and the frequency of discontinuity hampered the adoption of IP chemotherapy [4].In recent years, Intraperitoneal chemotherapy could be conveyed under hyperthermic circumstances that were termed hyperthermic intraperitoneal chemotherapy (HIPEC). Hyperthermia produced an increased number of lysosomes and lysosomal enzyme activity in malignant cells, resulting in

(c) The Author(s). 2019 Open Access This article is distributed under the terms of the Creative Commons Attribution 4.0 International License (http://creativecommons.org/licenses/by/4.0/), which permits unrestricted use, distribution, and reproduction in any medium, provided you give appropriate credit to the original author(s) and the source, provide a link to the Creative Commons license, and indicate if changes were made. The Creative Commons Public Domain Dedication waiver (http://creativecommons.org/publicdomain/zero/1.0/) applies to the data made available in this article, unless otherwise stated. 
enhanced cancer cell destruction [5]. Moreover, a decreased blood flow or complete vascular stasis were observed in tumors with hyperthermia therapy, which led to accelerated cancer cell death [6]. In contrast to IP chemotherapy without hyperthermia condition, HIPEC had following advantages 1) direct impairment against cancer cells 2) enhancement of the cytotoxicity of chemotherapy 3) inhibition of angiogenesis 4) improvement in denaturation of proteins 5) great tolerance without additional adverse effect [7-11] .However, due to the controversial impact of HIPEC for ovarian cancers, the role of HIPEC in the treatment of ovarian cancer is still debated. In 2015, a published meta-analysis suggested that the CRS + HIPEC +chemotherapy significantly improved 5-year overall survival rate compared to CRS + chemotherapy alone for the patients with primary ovarian cancer, but not for recurrent ovarian cancer [12]. Moreover, the meta-analysis did not provide enough available data to assess the influence of HIPEC on PFS, making it difficult to estimate the clinical benefit of HIPEC comprehensively. On the basis of additional articles, we analyzed all the qualified publications by meta-analysis to evaluate the prognostic impact of HIPEC on patients with ovarian cancers with the goal of identifying the patient population who would be most likely to benefit from HIPEC.

\section{Methods}

\section{Inclusion and exclusion criteria}

In this meta-analysis, comparative clinical trials were included, and the language was restricted to English. Articles were accepted if they complied with the following inclusion criteria: (1) Patients with a diagnosis of advanced primary or recurrent ovarian cancer. (2) Interventions were performed as follows: the experimental group included ovarian cancer patients who were administered by therapy with additional hyperthermic intraperitoneal chemotherapy (HIPEC), and the patients treated with traditional treatment without HIPEC were considered as the control group. (3) The study provides available data to calculate the HR of OS or PFS. Exclusion criteria included (1) Literature reviews, Systematic reviews. (2) Case reports or Case series. (3) Animal Experiments or Cell Experiments. (4) Phase I clinical trial. (5) Duplicate publication. (6) Studies include only the HIPEC group for ovarian cancer.

\section{Search strategy}

Two reviewers independently and simultaneously screened articles in the following databases: PubMed, Embase, Cochrane Library, Clinicaltrials.gov. MeSH terms and entry terms were used to search relevant articles.

The following is an example of the search strategy used on PubMed: (( (randomized controlled trial [pt] OR controlled clinical trial [pt] OR randomized [tiab] OR placebo [tiab] OR clinical trials as topic [mesh: noexp] OR randomly [tiab] OR trial [ti]) NOT (animals [mh] NOT humans [mh]))) AND $((((((($ “Hyperthermia, Induced”[Mesh]) OR $(((()((()(($ Therapy, Fever) OR Fever Therapy) OR Hyperthermia, Therapeutic)OR Therapeutic Hyperthermia) OR Thermotherapy) OR Induced Hyperthermia) OR Hyperthermic Intraperitoneal Chemotherapy) OR Chemotherapy, Hyperthermic Intraperitoneal) OR Hyperthermic Intraperitoneal Chemotherapies) OR intraperitoneal Chemotherapy, Hyperthermic) OR Hyperthermia, Local) OR Local Hyperthermia))) AND ((“Ovarian Neoplasms”[Mesh]) OR $\quad((()((c(c(c(c(c(($ Neoplasm, Ovarian) OR Ovarian Neoplasm) OR Ovary Neoplasms) OR Neoplasm, Ovary) OR Ovary Neoplasm) OR Neoplasms, Ovary) OR Neoplasms, Ovarian) OR Ovary Cancer) OR Cancer, Ovary) OR Cancers, Ovary) OR Ovary Cancers) OR Ovarian Cancer) OR Cancer, Ovarian) OR Cancers, Ovarian) OR Ovarian Cancers) OR Cancer of Ovary) OR Cancer of the Ovary)))) AND surgery)). Reviews of relevant studies were searched manually to find additional eligible studies. All the Publications in these databases are up to May 15, 2018.

\section{Quality assessment}

We estimated studies independently after reading the full text of each study. We used the Cochrane collaboration ROB tool to evaluate the quality of the involved randomized controlled trials (RCTs) [13] (Additional file 1:Table S1). The Newcastle-Ottawa scale (NOS) was employed to assess the quality of the observational study [14] (Additional file 1 :Table S2 ).

\section{Data extraction}

The necessary information of each trial contains the first author's name, year of publication, country, experimental design, the stage of cancer, mean age, the rate of OS, and the score of completeness of cytoreduction (CC). PFS was defined as the length of time from the start of treatment to the progression of the disease, and OS was defined as the length of time from the beginning of treatment to death. The score of CC was evaluated according to Sugarbaker [15]: CC0: no residual disease; CC1: the residual disease with nodules measuring less than $2.5 \mathrm{~mm}$; CC2: the residual disease with nodules measuring between 2.5 $\mathrm{mm}$ and $2.5 \mathrm{~cm}$; and CC3: the residual nodules greater than $2.5 \mathrm{~cm}$. Advanced primary ovarian cancer is defined as the stage of IC-IV in the initial diagnosis.

The hazard ratio (HR) was applied to evaluate the survival effects on PFS and OS. We extracted directly or calculated the hazard ratios and 95\% confidence intervals $(95 \% \mathrm{CI})$ from the survival curve based on the methodology of Tierney [16]. 


\section{Statistical analysis}

We evaluate all data using Review Manager 5.3 (Cochrane Collaboration) and STATA 12.0 software (Stata Corp., College Station, TX, USA). Inter-study heterogeneity was assessed using the Chi-square test and $I^{2}$. A $p$-value $>0.1$ or an $I^{2}<50 \%$ indicate that the heterogeneity is not statistically significant, thus the fixed-effect model is used. When the opposite happens, the random-effect model was applied correspondingly. Furthermore, we make use of sensitivity analysis to analyze the stability of pooled data and exclude studies at high risk of heterogeneity. Publication bias of studies was further appraised by Egger's tests and Begg's test.

\section{Results}

Characteristics of included studies and quality assessment According to the search strategy, we identified a total of 2383 papers. Of these,2370 references including duplication, diagnostic tests, case reports, review, and other irrelevant studies were excluded according to the exclusion criteria. A total of 13 articles were eligible for the meta-analysis. Among the included studies, there were two RCT $[17,18]$, and eleven observational studies. Our search steps are illustrated in Fig. 1.The general characteristic and scheme of thirteen articles were listed in Table 1 and Additional file 1 :TableS3. The detail of quality assessment for studies is shown in supplementary of Additional file 1 :TableS1 and Additional file 1: Table S2.

\section{The association between HIPEC and OS}

Twelve studies were eligible to assess the impact of HIPEC on OS. Pooled data demonstrated that there was an improvement in HIPEC groups compared with the groups without HIPEC treatment in all population ( $\mathrm{HR}=0.54,95 \% \mathrm{CI}: 0.45$ to 0.66 , $I^{2}=48 \%$ ) (Fig.2a). The subgroup analysis indicated that both advanced primary and recurrent patients with ovarian cancers gained significant OS benefit from HIPEC ( $\mathrm{HR}=0.59,95 \% \mathrm{CI}: 0.46$ to $0.72, \mathrm{HR}=0.45,95 \% \mathrm{CI}: 0.24$ to 0.83) (Table 2).

\section{The association between HIPEC and PFS}

Eight studies provided available data to calculate the HR of the PFS. As shown in Fig. 2b, the pooled data indicated that HIPEC improved PFS significantly compared

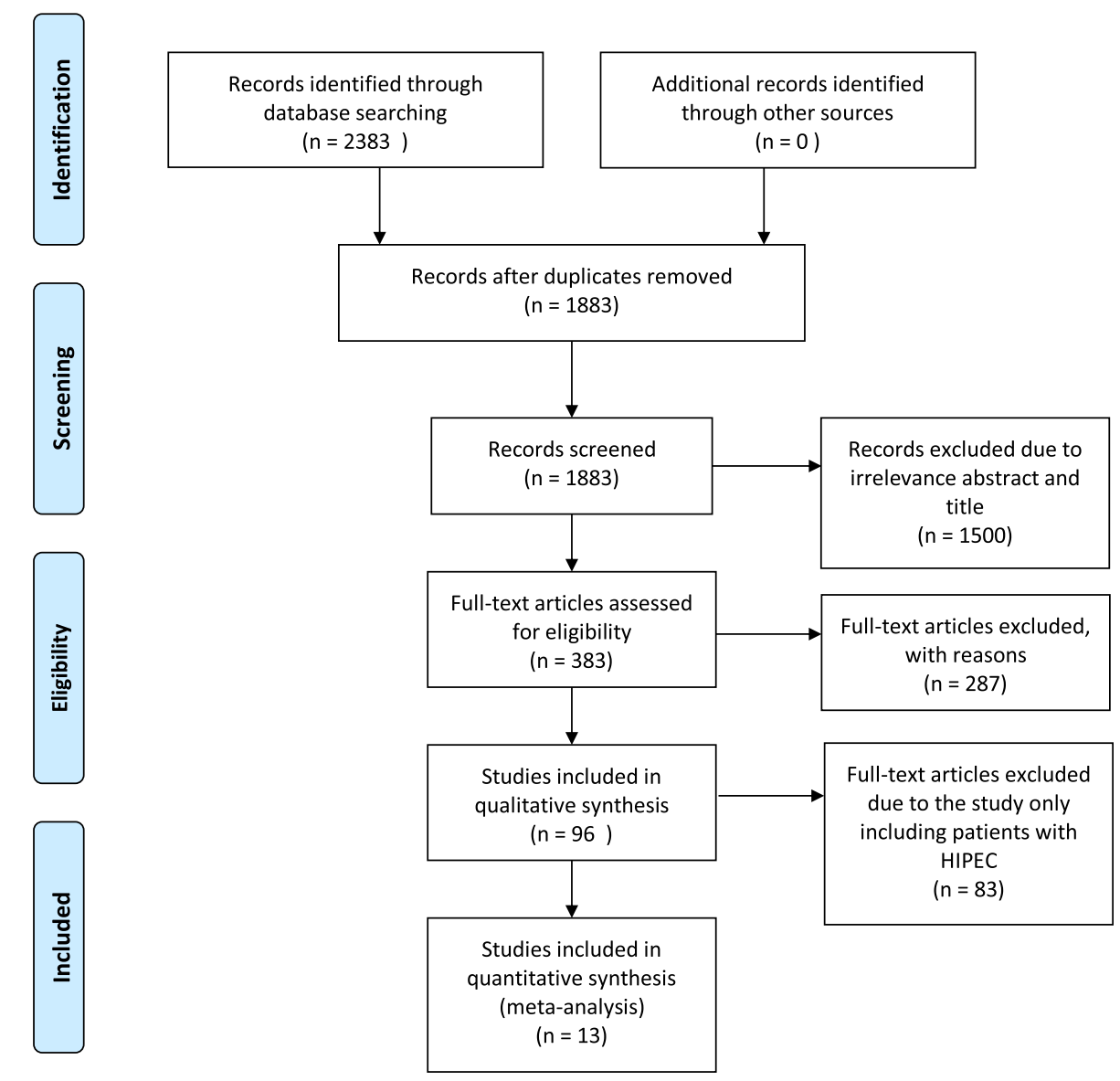

Fig. 1 Flow diagram of the literature search strategy 
Table 1 The characteristic of studies included in meta-analysis

\begin{tabular}{|c|c|c|c|c|c|c|c|c|}
\hline \multirow[t]{2}{*}{ Name } & \multirow[t]{2}{*}{ Arm } & \multirow[t]{2}{*}{ Original } & \multirow[t]{2}{*}{ Country } & \multirow{2}{*}{$\begin{array}{l}\text { Mean } \\
\text { age(year) }\end{array}$} & \multirow{2}{*}{$\begin{array}{l}\text { Patients } \\
\text { (Numbers) }\end{array}$} & \multicolumn{2}{|c|}{ Stage } & \multirow[t]{2}{*}{ OS (rate) } \\
\hline & & & & & & $\overline{|-| \mid}$ & $\overline{I I I-I V}$ & \\
\hline \multirow[t]{2}{*}{ Ki Sung Ryu2004 } & Control group & Primary & South Korea & 47.7 & 60 & 21 & 39 & $52.8 \%(5$-year) \\
\hline & Experimental group & & & 46.1 & 57 & 22 & 35 & 63.4\%(5-year) \\
\hline \multirow[t]{2}{*}{ J. GORI 2005} & Control group & Primary & Argentina & 57.0 & 19 & 0 & 19 & $42.1 \%(5$-year) \\
\hline & Experimental group & & & 55.5 & 29 & 0 & 29 & $55.2 \%(5$-year) \\
\hline \multirow[t]{2}{*}{ FranciscOC2009 } & Control group & Recurrence & Bulgaria & 54 & 12 & 0 & 12 & 17\% (5-year) \\
\hline & Experimental group & & & 54 & 14 & 0 & 14 & 57\% (5-year) \\
\hline \multirow[t]{2}{*}{ JIN HWI KIM 2010} & Control group & Primary & South Korea & 49 & 24 & 5 & 19 & 25\%(8-year) \\
\hline & Experimental group & & & 48 & 19 & 7 & 12 & $84.21 \%$ (8-year) \\
\hline \multirow[t]{2}{*}{ Rene Warschkow 2012} & Control Group & Primary or & Switzerland & 65 & 90 & 56 & 35 & $38.3 \%(5$-year) \\
\hline & Experimental group & Recurrence & & 58.9 & 21 & 17 & 4 & $72.5 \%(5$-year) \\
\hline \multirow[t]{2}{*}{ Anna Fagotti 2012} & Control Group & Recurrence & Italy & 55 & 37 & 5 & 32 & $37.8 \%(5$-year) \\
\hline & Experimental group & & & 51 & 30 & 4 & 26 & 76.7\%(5-year) \\
\hline \multirow[t]{2}{*}{ TAMAR SAFRA 2014} & Control Group & Recurrence & Israel & 54.3 & 84 & 7 & 76 & 45\%(5-year) \\
\hline & Experimental group & & & 54.3 & 27 & 2 & 25 & 79\%(5-year) \\
\hline \multirow[t]{2}{*}{ Jean-Franc, ois Le Brun 2014} & Control Group & Recurrence & France & $N R$ & 19 & 1 & 18 & 19.4\%(4-year) \\
\hline & Experimental group & & & $N R$ & 23 & 2 & 21 & 75.6\%(4-year) \\
\hline \multirow[t]{2}{*}{ Cascales-Campos, P. A2014 } & $\begin{array}{l}\text { Control } \\
\text { Group }\end{array}$ & Primary & Spain & 57 & 35 & 0 & 35 & NR \\
\hline & Experimental group & & & 57 & 52 & 0 & 52 & NR \\
\hline \multirow[t]{2}{*}{ J. Spiliotis 2015} & Control Group & Recurrence & Greece & 58.1 & 60 & 0 & 60 & 18\%(3-year) \\
\hline & Experimental group & & & 58.3 & 60 & 0 & 60 & 75\%(3-year) \\
\hline \multirow[t]{2}{*}{ Glauco Baiocchi 2016} & Control Group & Recurrence & Brazil & 58.4 & 50 & 10 & 40 & 49.5\%(5-year) \\
\hline & Experimental group & & & 51.6 & 29 & 2 & 27 & 49.7\%(5-year) \\
\hline \multirow[t]{2}{*}{ Alberto A. Mendivil 2017} & Control Group & Primary & USA & 62.9 & 69 & 0 & 69 & 75.3\%(3-year) \\
\hline & Experimental group & & & 59.8 & 69 & 0 & 69 & $82.6 \%(3-y e a r)$ \\
\hline \multirow[t]{2}{*}{ W.J. van Driel 2018} & Control Group & Primary & Netherlands & 63 & 122 & 0 & 122 & 38\%(5-year) \\
\hline & Experimental group & & & 61 & 118 & 0 & 118 & 50\%(5-year) \\
\hline
\end{tabular}

with patients without HIPEC therapy in all population $(\mathrm{HR}=0.45,95 \% \mathrm{CI}: 0.32$ to 0.62$)$. Among primary advanced ovarian cancers, the PFS in the HIPEC group was significantly longer ( $\mathrm{HR}=0.41,95 \% \mathrm{CI}: 0.32$ to 0.54 ). Interestingly, with regard to recurrent ovarian cancers, although the HIPEC improved the OS significantly, there was no association between HIPEC and PFS (HR $=0.55,95 \%$ CI:0.27 to 1.11 ).

The influence of HIPEC in stage III or IV ovarian cancer Based on the tumor stage, our pooled data also suggested that the prognostic benefit of HIPEC was also observed among patients with stage III or IV(HR $=0.64,95 \%$ CI:0.50 to $0.82, \mathrm{HR}=0.36,95 \%$ CI:0.20 to 0.65 ) (Table 2).

\section{The influence of $\mathrm{CC} 3$ in the meta-analysis}

In the retrieval process, we found that only studies of Warschkow and Baiocchi $[19,20]$ were reported to include patients with $\mathrm{CC} 3$, however, Warschkow eliminated patients with $\mathrm{CC} 3$ when they calculated the HR. When we excluded the Baiocchi's study, the $I^{2}$ of the pooled data decreased obviously, even the HIPEC showed useful effect on PFS of recurrent ovarian cancer, which was opposite to our pooled data (Table 2). The controversy result showed that the CC3 contributed to the high heterogeneity of pooled data and displayed a critical role in the therapy value of HIPEC.

\section{The influence of the CRS plus HIPEC timing in the meta- analysis}

As illustrated in Table 2, both primary HIPEC plus CRS followed by chemotherapies and interval combination of HIPEC and CRS after adjuvant chemotherapies indicated improved prognostic effect on OS ( $\mathrm{HR}=0.61,95 \%$ CI:0.45 to $0.83, \mathrm{HR}=0.47,95 \% \mathrm{CI}: 0.37$ to 0.61 ) and PFS ( $\mathrm{HR}=$ 0.29, $95 \% \mathrm{CI}: 0.1$ to 0.86 , $\mathrm{HR}=0.52$, 95\% CI:0.41 to 0.65 ). 


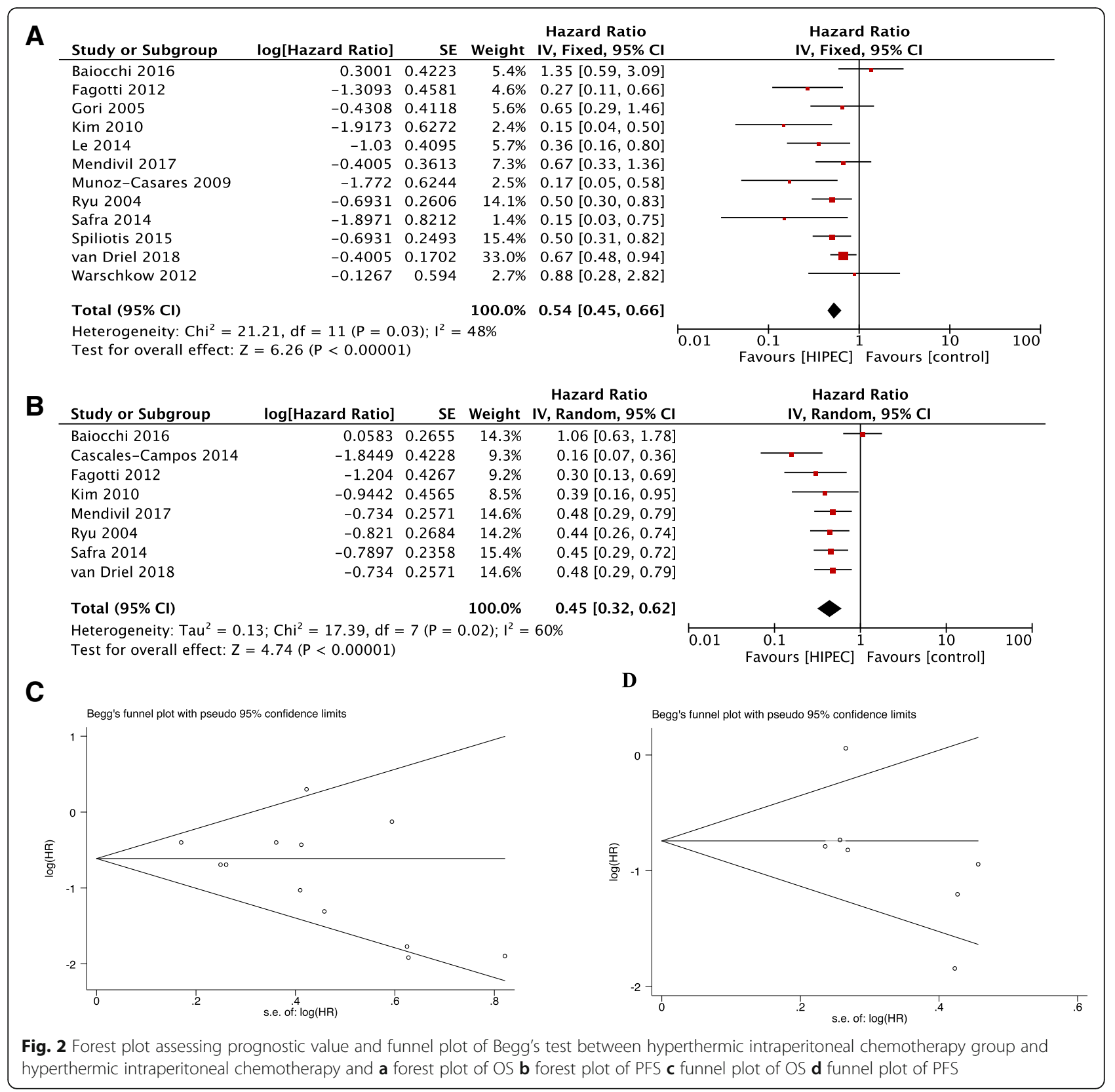

\section{Sensitive analysis}

To investigate the impact of the individual study on the pooled data, we conducted a sensitivity analysis in which every study was deleted consecutively to test the stability of the data. The result of OS and PFS was robust, sequential omission of data from any individual study did not affect the results (Fig. 3a-b).

\section{Publication bias}

As shown in Fig. 2c-d, the Begg's test and Egger's test were applied to evaluate the bias of publication, and there was no significant bias in $\mathrm{PFS}(P \mathrm{~B}=0.216, P \mathrm{E}=0.147)$ as well as $\mathrm{OS}(P \mathrm{~B}=0.086, P \mathrm{E}=0.097)$.

\section{Discussion}

To date, there is increasing evidence that the combination of CRS and HIPEC enhances the prognosis of ovarian cancer significantly [19, 21-27]. However, in recent years, some studies demonstrated that the HIPEC did not show any improvement in OS compared with the therapy without the HIPEC $[20,28]$. Thus, whether HIPEC offered benefit to patients is still under debate. Although the previous meta-analysis had revealed the association between HIPEC and better clinical prognosis, the positive effect was only applicable to the primary advanced ovarian cancer. This time, we made use of HR [29] instead of OR in the previous meta-analysis to 


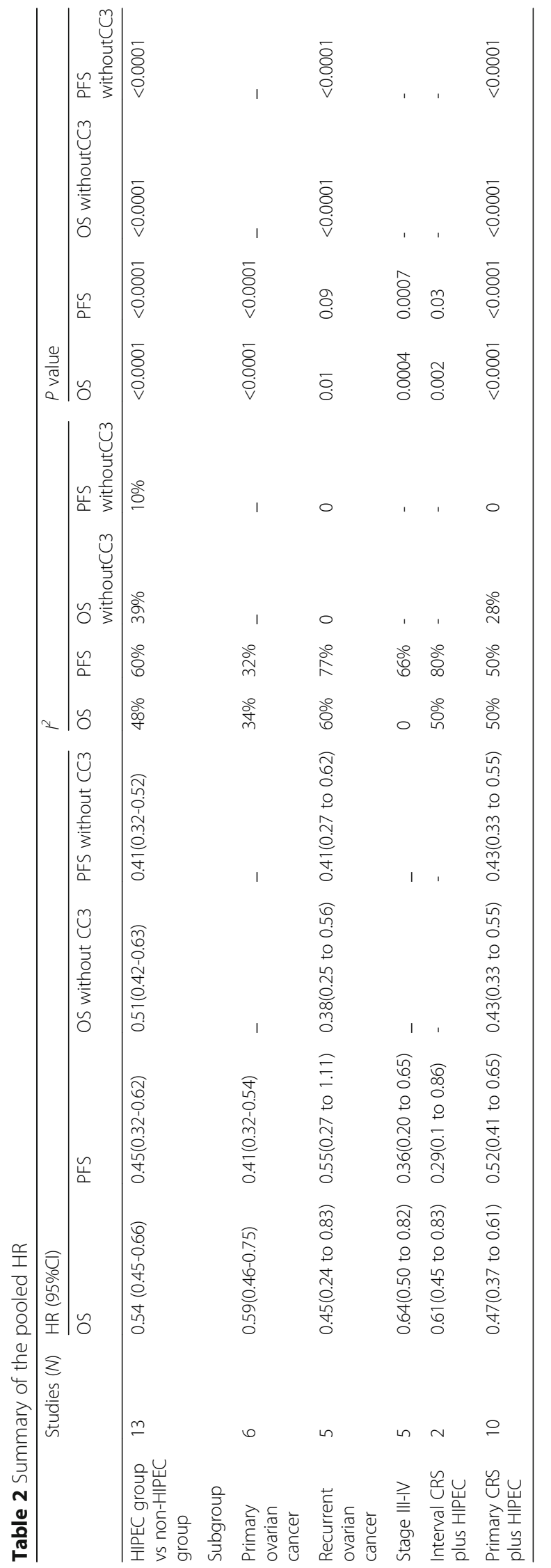




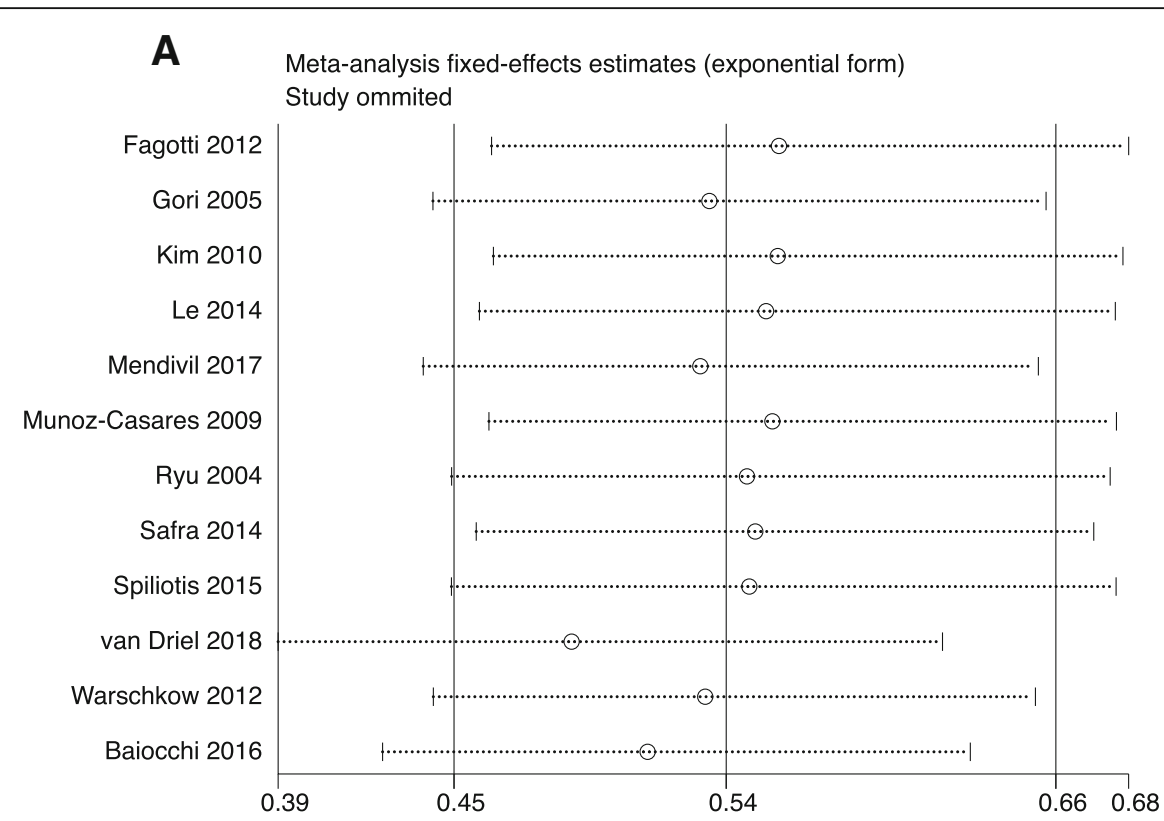

B Meta-analysis random-effects estimates (exponential form) Study ommited

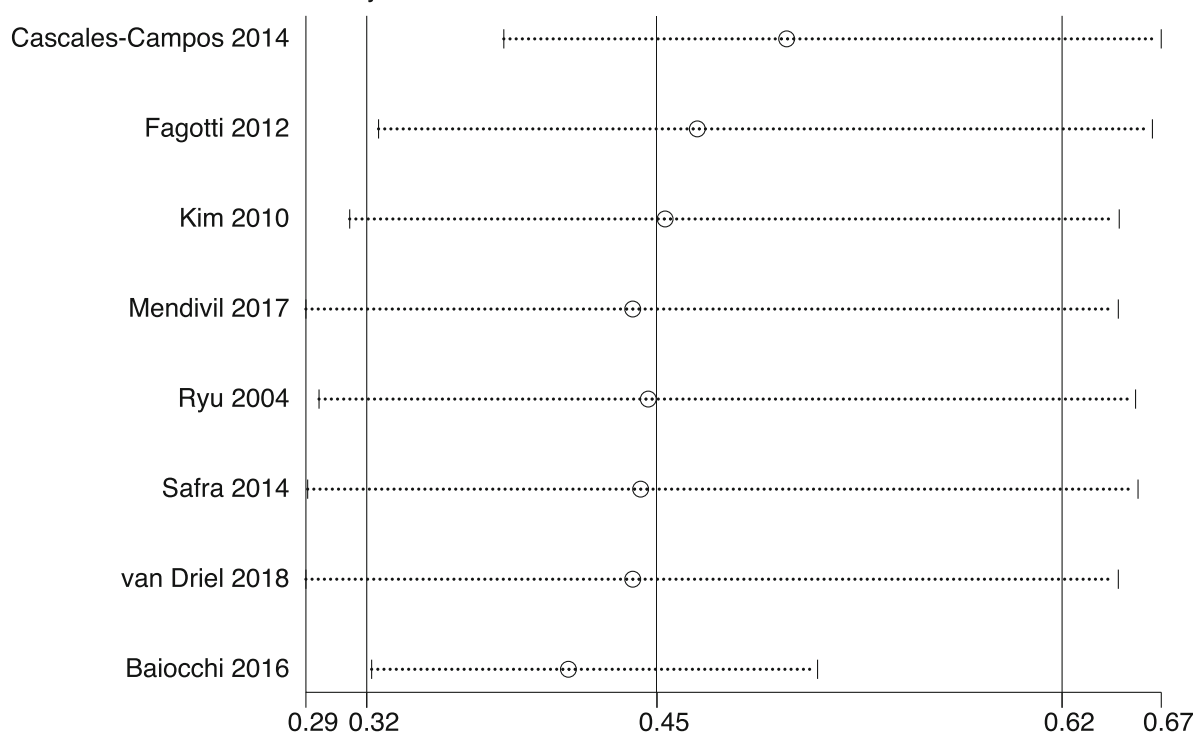

Fig. 3 Sensitive analysis between HIPEC group and non-HIPEC group a OS $\mathbf{b}$ PFS

describe the prognostic effect of HIPEC. Moreover, we found that a total of eight studies have qualified data to calculate the HR of PFS which omitted in the previous meta-analysis. The current meta-analysis demonstrated that the HIPEC not only improved OS significantly but also prolonged the PFS in all population. Subgroup analysis indicated that HIPEC was associated with better clinical outcome whether primary or recurrent patients. Even stage III or IV ovarian cancer patients could benefit from HIPEC. Noticeably, deleting the study including patients with $\mathrm{CC} 3$ could result in the decrease of heterogeneity (Table 2), which was consistent to the previous literatures that the score of $\mathrm{CC}$ was one of the most critical prognostic factors in advanced ovarian cancer when HIPEC followed a cytoreductive surgery [30, 31].

There were some limitations in the current meta-analysis. First, we searched the publications as complete as possible, only papers published in English were eligible, which may lead to selection bias. Secondly, the shortage of RCT was likely to increase the risk of bias. Thirdly, most of the studies were from observational studies, which might compromise 
the meta-analysis. Fourthly, factors including whether ovarian cancer resists platinum or not, pathological classification of ovarian cancer, the agency of chemotherapy medicine, and the completeness of cytoreduction were needed to be stratified further to determinate the most suitable candidates for HIPEC. Additionally, among 13 included studies, only van Driel reported the information about adverse events (AE) between HIPEC arm and non-HIPEC arm. There were no significant differences of $\mathrm{AE}$ between the two groups. For the HIPEC treatment group, the most common AE included Abdominal pain, Nausea, Vomiting, Fatigue, Pain. Most common $\mathrm{AE}$ of grade 3 or 4 were Abdominal pain, infection, ileus [18]. Kim [24] and Mendivil [28] also reported a similar situation of toxicity and AE on HIPEC therapy. Finally, we hope that more RCT and well-designed observational studies are incorporated into the meta-analysis to ascertain and evaluated the effect and the toxicity of HIPEC in ovarian cancer.

\section{Conclusion}

Summary, HIPEC-based regimens might result in favorable PFS and OS for patients with advanced primary ovarian cancer. With regards to recurrent ovarian cancers, HIPEC only improved the OS but did not elicit positive value on the PFS. Additionally, it was associated with better clinical prognostic outcome among Stage III or IV ovarian cancer patients with the initial diagnosis. The CC3 might display a critical role in reducing the effect of HIPEC.

\section{Additional file}

Additional file 1: Table S1. Quality assessment of included RCT. Table S2.The Newcastle-Ottawa scale(NOS)scores of the included non-RCTs. Table S3. The scheme of studies included in meta-analysis. (DOCX 24 kb)

\section{Abbreviations \\ CC: Completeness of cytoreduction; Cl: Confidence interval: CRS: Cytoreductive surgery; HIPEC: The adenomatous polyposis coli; HR: Hazard ratio; OS: Overall survival; PFS: Progression free survival; RCT: Randomized controlled trial}

\section{Acknowledgements}

We would like to thank all authors who provided published data for our meta-analysis.

\section{Funding}

This study was supported by the National Natural Science Funds(81571455), projects of the ministry of science and technology(2015DFR31070), Special plan of clinical medicine development of Beijing medical administration bureau(ZYLX201713), Ministry of science and technology(2017YFC1001204)

\section{Availability of data and materials}

All data is available in this paper.

\section{Authors' contributions}

GYZ and YMZ make contribute to data analysis and the completion of the article. CDL contributes to the document selection. GMC and RC contribute to the inclusion and exclusion criteria. ZYZ contribute to the design of the meta-analysis. All authors approved the final manuscript.
Ethics approval and consent to participate

Not applicable.

\section{Consent for publication}

Not applicable.

Competing interests

The authors declare that they have no competing interests.

\section{Publisher's Note}

Springer Nature remains neutral with regard to jurisdictional claims in published maps and institutional affiliations.

\section{Author details}

'Department of Obstetrics and Gynecology, Beijing Chaoyang Hospital, Capital Medical University, No.8, industrial south road, Chaoyang District, Beijing, China. ${ }^{2}$ Department of Oncology, Affiliated Hospital of Guangdong Medical University, Zhanjiang, Guangdong Province, China.

Received: 28 November 2018 Accepted: 4 April 2019

Published online: 17 April 2019

References

1. Siegel RL, Miller KD, PhD AJD. Cancer statistics, 2017. Ca A Cancer Journal for Clinicians. 2017:67(1).

2. Bijelic L, Jonson A, Sugarbaker PH. Systematic review of cytoreductive surgery and heated intraoperative intraperitoneal chemotherapy for treatment of peritoneal carcinomatosis in primary and recurrent ovarian cancer. Annals of Onco Off J Eur Soc Med Oncol. 2007;18(12):1943.

3. Tewari D, Java JJ, Salani R, Armstrong DK, Markman M, Herzog T, Monk BJ, Chan JK. Long-term survival advantage and prognostic factors associated with intraperitoneal chemotherapy treatment in advanced ovarian cancer: a gynecologic oncology group study. J Clin Oncol Off J Am Soc Clin Oncol. 2015;33(13):1460-6.

4. Wright AA, Cronin A, Milne DE, Bookman MA, Burger RA, Cohn DE, Cristea MC, Griggs JJ, Keating NL, Levenback CF. Use and effectiveness of intraperitoneal chemotherapy for treatment of ovarian Cancer. J Clin Onco Off J Am Soc Clin Oncol. 2015;33(26):2841-7.

5. Gonzalez-Moreno S, Gonzalez-Bayon LA, Ortega-Perez G. Hyperthermic intraperitoneal chemotherapy: rationale and technique. World journal of gastrointestinal oncology. 2010;2(2):68-75. https://doi.org/10.4251/wjgo.v2.i2.68.

6. Dudar TE, Jain RK. Differential response of normal and tumor microcirculation to hyperthermia. Cancer Res. 1984;44(2):605-12.

7. Glehen O, Mohamed F, Gilly FN. Peritoneal carcinomatosis from digestive tract cancer: new management by cytoreductive surgery and intraperitoneal chemohyperthermia. Lancet Oncol. 2004;5(4):219-28.

8. Sugarbaker PH. Intraperitoneal chemotherapy and cytoreductive surgery for the prevention and treatment of peritoneal carcinomatosis and sarcomatosis. Semin Surg Oncol. 2015;14(3):254-61.

9. Panteix G, Beaujard A, Garbit F, Chaduiron FC, Guillaumont M, Gilly F, Baltassat $P$, Bressolle F. Population pharmacokinetics of cisplatin in patients with advanced ovarian cancer during intraperitoneal hyperthermia chemotherapy. Anticancer Res. 2002;22(2B):1329-36.

10. Pj VDV, Van dVN, Zoetmulder FA, van Goethem AR, Van TO, Ww TBH, Beijnen $J H$, Bartelink H, Begg AC. Intraperitoneal cisplatin with regional hyperthermia in advanced ovarian cancer: pharmacokinetics and cisplatinDNA adduct formation in patients and ovarian cancer cell lines. Eur J Cancer. 1998:34(1):148-54.

11. Ranieri G, Ferrari C, Di Palo A, Marech I, Porcelli M, Falagario G, Ritrovato F, Ramunni L, Fanelli M, Rubini G, Gadaleta CD. Bevacizumabbased chemotherapy combined with regional deep capacitive hyperthermia in metastatic Cancer patients: a pilot study. Int J Mol Sci. 2017;18(7). https://doi.org/10.3390/ijms18071458.

12. Huo YR, Richards A, Liauw W, Morris DL. Hyperthermic intraperitoneal chemotherapy (HIPEC) and cytoreductive surgery (CRS) in ovarian cancer: a systematic review and meta-analysis. European Journal of Surgical Oncology the Journal of the European Society of Surgical Oncology \& the British Association of Surgical Oncology. 2015;41(12):1578-89.

13. Higgins JE (2008) Cochrane Handbook for Systematic Reviews of Interventions. http://wwwcochrane-handbookorg/ 5 (2):S38. 
14. Stang A. Critical evaluation of the Newcastle-Ottawa scale for the assessment of the quality of nonrandomized studies in meta-analyses. Eur J Epidemiol. 2010;25(9):603-5.

15. Sugarbaker PH. Peritonectomy procedures. Cancer Treat Res. 2007;134:247-64.

16. Tierney JF, Stewart LA, Ghersi D, Burdett S, Sydes MR. Pract methods inc summ time-to-event data into meta-analysis. 2007;8(1):16.

17. Spiliotis J, Halkia E, Lianos E, Kalantzi N, Grivas A, Efstathiou E, Giassas S. Cytoreductive surgery and HIPEC in recurrent epithelial ovarian cancer: a prospective randomized phase III study. Ann Surg Oncol. 2015;22(5):1570-5. https://doi.org/10.1245/s10434-014-4157-9.

18. van Driel WJ, Koole SN, Sikorska K, Schagen van Leeuwen JH, Schreuder HWR, Hermans RHM, de Hingh I, van der Velden J, Arts HJ, Massuger L, Aalbers AGJ, Verwaal VJ, Kieffer JM, Van de Vijver KK, van Tinteren H, Aaronson NK, Sonke GS. Hyperthermic intraperitoneal chemotherapy in ovarian Cancer. N Engl J Med. 2018;378(3):230-40. https://doi.org/10.1056/NEJMoa1708618.

19. Warschkow R, Tarantino I, Lange J, Muller SA, Schmied BM, Zund M, Steffen T. Does hyperthermic intraoperative chemotherapy lead to improved outcomes in patients with ovarian cancer? A single center cohort study in 111 consecutive patients. Patient safety in surgery. 2012;6(1):12. https://doi. org/10.1186/1754-9493-6-12.

20. Baiocchi G, Ferreira FO, Mantoan H, da Costa AA, Faloppa CC, Kumagai LY, de Mello CA, Takahashi RM, Nakagawa WT, Aguiar S Jr, Lopes A. Hyperthermic intraperitoneal chemotherapy after secondary Cytoreduction in epithelial ovarian Cancer: a single-center comparative analysis. Ann Surg Oncol. 2016;23(4):1294-301. https://doi.org/10.1245/s10434-015-4991-4.

21. Ryu KS, Kim JH, Ko HS, Kim JW, Ahn WS, Park YG, Kim SJ, Lee JM. Effects of intraperitoneal hyperthermic chemotherapy in ovarian cancer. Gynecol Oncol. 2004;94(2):325-32. https://doi.org/10.1016/j.ygyno.2004.05.044.

22. Gori J, Castano R, Toziano M, Habich D, Staringer J, De Quiros DG, Felci N (2005) Intraperitoneal hyperthermic chemotherapy in ovarian cancer. Intl j gynecol cancer : official journal of the International Gynecological Cancer Society 15 (2):233-239. doi:https://doi.org/10.1111/j.1525-1438.2005.15209.x.

23. Munoz-Casares FC, Rufian S, Rubio MJ, Diaz CJ, Diaz R, Casado A, Arjona A, Munoz-Villanueva MC, Muntane J. The role of hyperthermic intraoperative intraperitoneal chemotherapy (HIPEC) in the treatment of peritoneal carcinomatosis in recurrent ovarian cancer. Clinical \& translational oncology : official publication of the Federation of Spanish Oncology Societies and of the National Cancer Institute of Mexico. 2009;11(11):753-9.

24. Kim JH, Lee JM, Ryu KS, Lee YS, Park YG, Hur SY, Lee KH, Lee SH, Kim SJ. Consolidation hyperthermic intraperitoneal chemotherapy using paclitaxel in patients with epithelial ovarian cancer. J Surg Oncol. 2010;101(2):149-55. https://doi.org/10.1002/jso.21448

25. Fagotti A, Costantini B, Petrillo M, Vizzielli G, Fanfani F, Margariti PA, Turco LC, Piovano E, Scambia G. Cytoreductive surgery plus HIPEC in platinumsensitive recurrent ovarian cancer patients: a case-control study on survival in patients with two year follow-up. Gynecol Oncol. 2012;127(3):502-5. https://doi.org/10.1016/j.ygyno.2012.09.020.

26. Le Brun JF, Campion L, Berton-Rigaud D, Lorimier G, Marchal F, Ferron G, Oger AS, Dravet F, Jaffre I, Classe JM. Survival benefit of hyperthermic intraperitoneal chemotherapy for recurrent ovarian cancer: a multiinstitutional case control study. Ann Surg Oncol. 2014;21(11):3621-7. https:// doi.org/10.1245/s10434-014-3693-7.

27. Safra T, Grisaru D, Inbar M, Abu-Abeid S, Dayan D, Matceyevsky D, Weizman A, Klausner JM. Cytoreduction surgery with hyperthermic intraperitoneal chemotherapy in recurrent ovarian cancer improves progression-free survival, especially in BRCA-positive patients- a casecontrol study. J Surg Oncol. 2014;110(6):661-5. https://doi.org/10.1002/ jso.23688

28. Mendivil AA, Rettenmaier MA, Abaid LN, Brown JV, Mori KM, Lopez KL, Goldstein $\mathrm{BH}$. Consolidation hyperthermic intraperitoneal chemotherapy for the treatment of advanced stage ovarian carcinoma: a 3 year experience. Cancer Chemother Pharmacol. 2017;80(2):405-10. https://doi.org/10.1007/ s00280-017-3376-8.

29. Trinquart L, Jacot J, Conner SC, Porcher R (2016) Comparison of treatment effects measured by the Hazard ratio and by the ratio of restricted mean survival times in oncology randomized controlled trials. Journal of Clinical Oncology Official Journal of the American Society of Clinical Oncology 34 (15).

30. Ceelen WP, Van Nieuwenhove Y, Van Belle S, Denys H, Pattyn P. Cytoreduction and hyperthermic intraperitoneal chemoperfusion in women with heavily pretreated recurrent ovarian cancer. Ann Surg Oncol. 2012; 19(7):2352-9. https://doi.org/10.1245/s10434-009-0878-6.

31. Magge D, Ramalingam L, Shuai Y, Edwards RP, Pingpank JF, Ahrendt SS, Holtzman MP, Zeh HJ, Bartlett DL, Choudry HA. Hyperthermic intraperitoneal chemoperfusion as a component of multimodality therapy for ovarian and primary peritoneal cancer. J Surg Oncol. 2017;116(3):320-8. https://doi.org/10.1002/jso.24666
Ready to submit your research? Choose BMC and benefit from:

- fast, convenient online submission

- thorough peer review by experienced researchers in your field

- rapid publication on acceptance

- support for research data, including large and complex data types

- gold Open Access which fosters wider collaboration and increased citations

- maximum visibility for your research: over $100 \mathrm{M}$ website views per year

At BMC, research is always in progress.

Learn more biomedcentral.com/submissions 